\title{
Managing Radial Nerve Injuries Associated with Humeral Fracture
}

\author{
VLAD CARBUNARU1, ANA MARIA OPROIU ${ }^{1}$, ADRIAN BARBILIAN ${ }^{3}$, CHEN FENG-IFRIM ${ }^{2 *}$, \\ ALEXANDRA CIOTEI ${ }^{1}$ \\ ${ }^{1}$ Carol Davila University of Medicine and Pharmacy Bucharest, 37 Dionisie Lupu Str.,020021, Bucharest, Romania \\ ${ }^{2}$ Carol Davila University of Medicine and Pharmacy Bucharest, Department of Traditional Medicine, 8 Eroilor Sanitari \\ Blvd., 050474, Bucharest, Romania \\ ${ }^{3}$ Carol Davila Central Universitary Emergency Military Hospital, 134 Calea Plevnei Str., 010825, Bucharest, Romania
}

The overall prevalence of radial nerve injury after humeral shaft fractures is up to $18 \%$ representing the most common peripheral nerve injury associated with long bone fractures. Spiral or oblique fractures of the junction between the middle and distal third of the humeral shaft are at greater risk for radial nerve injury. Iatrogenic damage to the radial nerve may also occur during manipulations of closed reduction. A prospective study between 2017-2019 following 5 patients (all male, with ages between 30 and 56 years old), who were treated at our clinic for complete radial nerve palsy after a high-energy fracture of the humerus. All the patients were followed-up for a mean of 6 months (range 4 - 15 months) post op. The first 3 cases showed the initial signs of recovery 4 weeks after the operation. In the last 2 cases a palliative radial intervention was required. The consequences of the radial nerve palsy associated with humeral fractures is strongly related to trauma mechanism. In high energy fractures, severe contusion or transection of the nerve must be expected. In this case, nerve recovery is unlikely and the patients should be informed of the poor prognosis and the need of tendon transfers.

Keywords: humeral fracture, compression, upper limb, radial nerve, callus

Fractures of the humerus are often complicated with radial nerve palsy. The overall prevalence of radial nerve injury after humeral shaft fractures is up to $18 \%$ representing the most common peripheral nerve injury associated with long bone fractures [1-5]. This is caused by the relatively fixed position of the radial nerve and the direct contact with the periosteum of the humerus as the nerve courses through the middle and distal thirds of the upper arm and by the nerve's diminished mobility where it pierces the lateral intermuscular septum. As such, at this level the bone ends can easily entrap, contuse, or even lacerate the radial nerve, varying from neurapraxias to complete neurotmesis.

Spiral or oblique fractures of the junction between the middle and distal third of the humeral shaft are at greater risk for radial nerve injury [6]. Iatrogenic damage to the radial nerve may also occur during manipulations of closed reduction or at the time of surgical intervention, during internal fixation with a intramedullary nailing or compression plate (7-9).

Treatment is often expectant (non-operative), though surgery is also sometimes necessary by a variety of often imaginative procedures. Because radial nerve injuries are the least debilitating of the upper limb nerve injuries, results are usually satisfactory[10].

\section{Experimental part}

\section{Patients and methods}

A prospective study between 2017-2019 following 5 patients (all male, with ages between 30 and 56 years old), who were treated at our institution for complete radial nerve palsy after a high-energy fracture of the humerus. In all cases, the fracture was stabilized and no other complications except the radial palsy. Baseline electrophysiological studies (i.e. nerve conduction velocity studies and electromyography) conducted before admittance showed a complete motor paralysis of the nerve and all had an absent Tinel's sign at each clinical examination.

\footnotetext{
*email:adsm.adsm@yahoo.com
} All authors have participated equally in developing this article 


\section{Operative procedure}

Case 1: A 41 year old male, with a 4 months old high energy transverse diaphyseal fracture of the left humerus and faulty soft tissues following a car accident was treated with plating.

The same anterolateral approach used for plating, was used during our surgical exploration where we found contusion of the radial nerve and perineurial adhesions of a small segment at the level of the humeral fracture (Fig 1).

External neurolysis was practiced (Fig 2) .

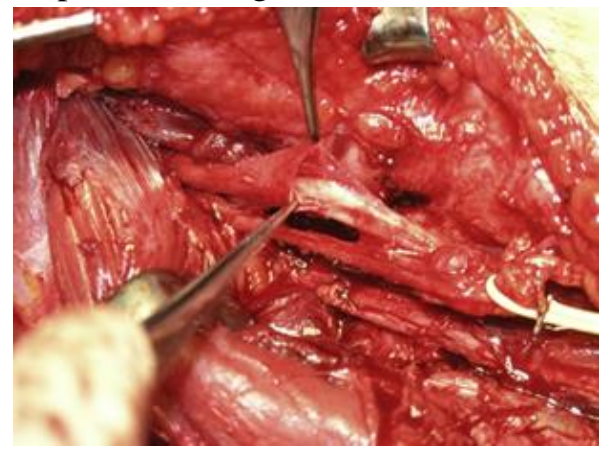

Fig.1. Perineural adhesion of the radial nerve to the humerus

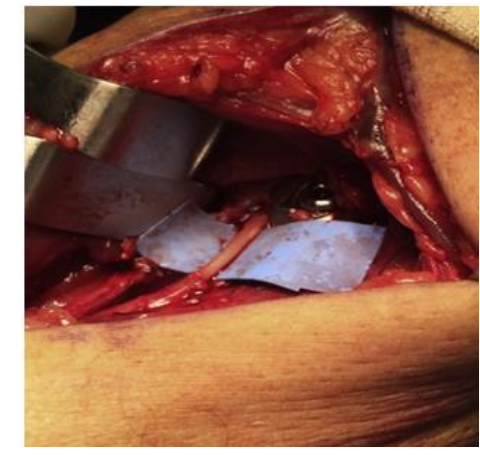

Fig.2. Neurolysis of the radial nerve

Case 2: A 38 year old male, with a 3 months old closed fracture of the right humeral shaft following a recreational arm wrestling match was treated with 2 non-staggered plates.

Upon surgical exploration via dorsal approach, a partially lacerated nerve draped over a loose compression plate.

Treatment associated the refixation of the plate and embedment of the nerve in the triceps muscle.

Case 3: A 40 year old male, with a 3 month old fracture of the humeral shaft following a car crush was treated with external fixator.

During surgical exploration, the distal pin of the external fixator was found to ran through the brachioradial muscle into the body of the radial nerve destroying $15 \%$ of its circumference (Fig. 3).

The pin was removed and reattached after releasing the nerve and embedding it in the triceps muscle.

Case 4: A 56 year old male with a six month old fracture of the left humeral shaft was treated with internal fixation after crush in the conveyor belt.

Surgical exploration had a posterior approach through a lateral para-tricipital window revealing the nerve enveloped in the fracture callus more than $8 \mathrm{~cm}$ with the impossibility of finding the proximal end (Fig. 4).

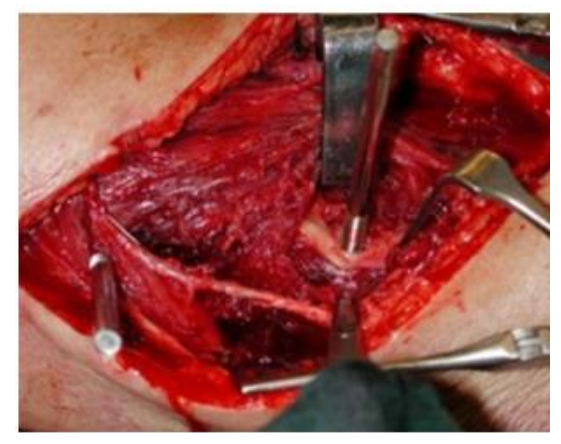

Fig.3. Distal pin winded up in the radial nerve

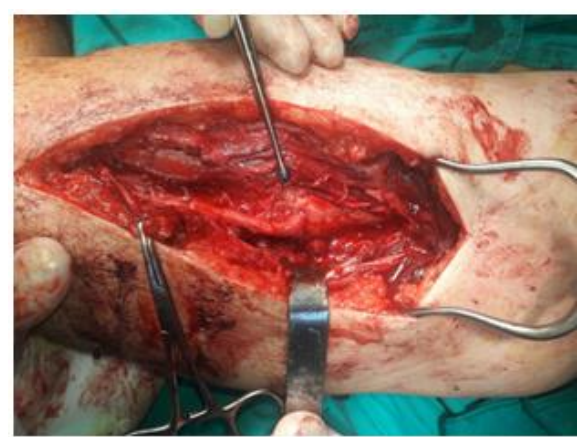

Fig.4. Radial nerve buried in the fracture callus

A follow-up tendon transfer procedure was carried out: flexor ulnaris carpi to extensor ulnaris carpi, flexor superficialis of middle finger to extensor digitorum communis, palmaris longus to extensor pollici longus (Fig.5, Fig.6, Fig.7). 


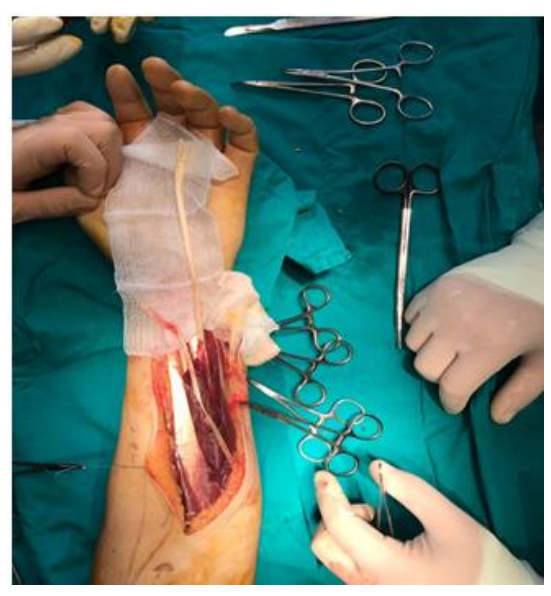

Fig.5. Presenting the donor tendons. From left to right: palmaris longus, flexor superficialis middle finger and flexor ulnaris carpi

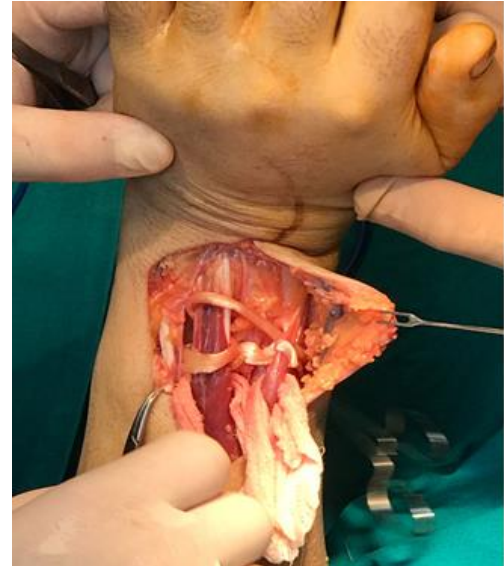

Fig.6. Tenoplasty of the extensor digitorum communis and extensor pollici longus by Pulvertaft technique

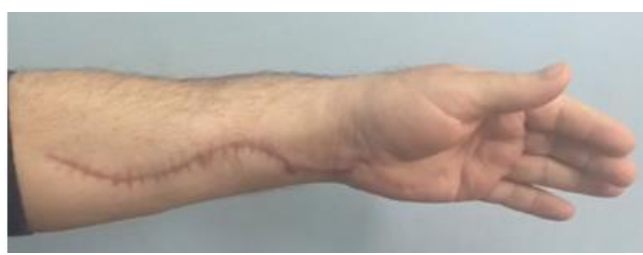

Fig.7. Active extension of the wrist, thumb and fingers 6 weeks post op.

Case 5: A 30 year old male, with a 12 month old chainsaw trauma which required open reduction and fixation of the humerus, anastomoses of the brachial artery with venous grafting and neurorrhaphy of median nerve and ulnar nerve, with the impossibility of finding the radial nerve ends, presented for second intervention in our clinic.

A palliative radial intervention practicing tendon transfer was used.

We transferred the pronator teres tendon to extensor carpi radialis tendon, flexor carpi radialis tendon to extensor digitorum communis and plamaris longus to extensor pollicis longus (Fig.8, Fig.9).

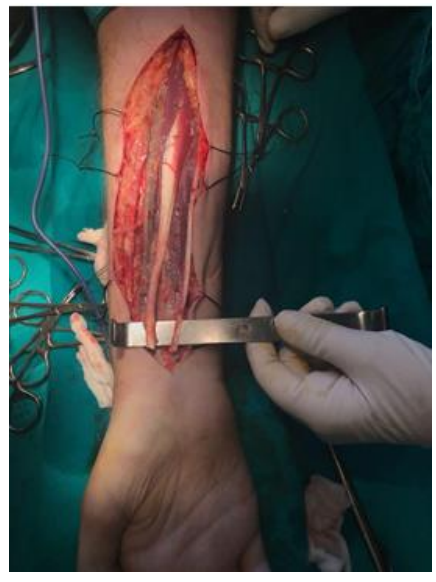

Fig.8. Presenting the donor tendons. From left to right: pronator teres, flexor radialis carpi and palmaris longus

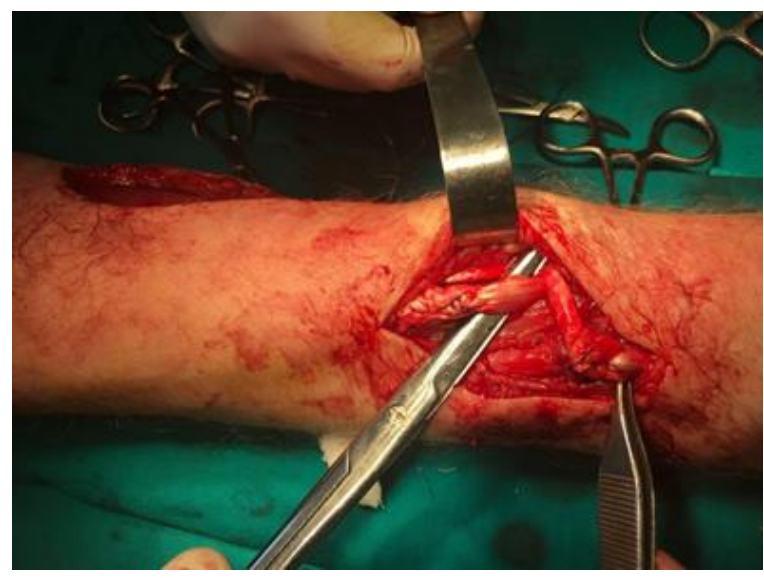

Fig.9. Tenoplasty of the extensor carpi radialis (over the scissors tip), extensor digitorum communis (forceps) by Pulvertaft technique

Postoperative follow-up examination included radiographic evaluation of the fracture, physical examination (i.e. Tinel's sign), and monthly electrophysiological studies for motor and sensory nerve recovery. 


\section{Results and discussions}

All the patients were followed-up for a mean of 6 months (range 4 - 15 months) post op. The first 3 cases showed the initial signs of recovery 4 weeks after the operation. Full nerve recovery was achieved in a mean of 19 weeks (range 1622 weeks) with a slight sensory discomfort in the $3^{\text {rd }}$ case. An advancing Tinel's sign was a good predictor for nerve recovery

In the last 2 cases where palliative radial intervention practicing tendon transfer was used, the imobilization was removed after approximately 4 weeks and a volar custom splint made by a hand therapist was applied with extension slings for the MP joint of the fingers. Active range-of-motion exercises of the fingers were begun at 3 to 4 weeks, and the wrist at 6 weeks.

Splinting as protection yielded excellent results and was done for 8 to 12 weeks postoperatively .

This cases highlights the necessity of a postreduction examination of the fracture. Nerve function should always be thoroughly assessed before and after reduction, with complete documentation in the medical record.

To ensure accuracy, any patient who requires conscious sedation for reduction must return to full consciousness and alertness before obtaining the postreduction exam.

Radial nerve injury associated with a humeral shaft fracture is a very important injury pattern among trauma patients with an incidence up to $18 \%$ [3]. These injuries can be either primary or secondary depending on the timing of the palsy presentation. Early surgical exploration of the nerve is generally indicated for cases in which there was an open fracture, fractures that cannot achieve an adequate closed reduction requiring open reduction, fractures associating a vascular injury or a severe soft tissue injury[11].

Patients who demonstrate a primary radial nerve palsy have a reported spontaneous recovery rate of over 70\% [12]. In the management of nerve palsy, nerve conduction examination with electrophysiological studies could be obtained at three months post injury, as motor potential should be recovered by this point, and these nerve conduction data will enable the clinician to determine if the injury should require surgical intervention. Early exploration revealing a nerve injury that can be repaired can lead to a quicker return to function and better nerve recovery. Degeneration of the motor endplate and irreversible muscle atrophy occurs if sufficient reinnervation is not present within 12-18 months after injury [13]. Poor functional recovery has been demonstrated in experimental studies when nerve repair is delayed for 6 months due to decreased motor neuron regeneration capacity [14-16].

\section{Conclusions}

Tendon transfer remains an essential technique in irreparable or long-standing radial nerve palsies for hand function restoration. Because the first signs of nerve recovery can be quite delayed, patience is merited before considering tendon transfers. A waiting period of 12 months is usually sufficient to see any evidence of nerve regeneration. Following a radial nerve injury, the extrinsic extensor function of the hand and wrist is lost, resulting in an inability to extend the fingers and wrist. It affects grip strength and has a large influence on thumb usage. Tendon transfer surgery must restore wrist, thumb and finger function without inflicting other motor deficits on the hand [15,18]. It is important that the joints have achieved good passive mobility in order to achieve optimal function post-tendon transposition. The donor muscles are tested for strength before surgery, and must come from a region unaffected by the pathology[19].

Modern medicine sheds light on biological therapies and nerve regeneration [20-22]. Research is being conducted with pluripotent stem cells and nerve conduits with promising developments using human amniotic membranes loaded with human umbilical cord mesenchymal stem cells in radial nerve repair [19,23].

\section{References}

1. POLLOCK, F.H., DRAKE, D., BOVILL, E.G., DAY, L., TRAFTON, P.G., Treatment of radial neuropathy associated with fractures of the humerus. J Bone Joint Surg 1981;63:239-43.

2. AMILLO, S., BARRIOS, R.H., MARTINEZ-PERIC, R., LOSADA, J.I., Surgical treatment of the radial nerve lesions associated with fractures of the humerus. J Orthop Trauma 1993;7:211-5.

3. EKHOLM, R., ADAMI, J., TIDERMARK, J., et al. Fractures of the shaft of the humerus. An epidemiological study of 401 fractures. J Bone Joint Surg Br 2006;88(11): 1469-73.

4. BOSTMAN, O., BAKALIM, G., VAINIONPA, S., WILPPULA, E., PATIALA, H., ROKKANEN, P., Radial palsy in shaft fracture of the humerus. Acta Orthop Scand 1986;57(4):316-319.

5. DUNCAN, D.M., JOHNSON, K.A., MONKMAN, G.R., Fracture of the humerus and radial nerve palsy. Minn Med 1974;57(8):659-662.

6. SHAO, Y.C., HARWOOD, P., GROTZ, M.R.W., LIMB, D., GIANNOUDIS, P.V., Radial nerve palsy associated with fractures of the shaft of the humerus. A systematic review. J Bone Joint Surg Brit Vol 2005;87:1647-52

7. FARRAGOS, A., SCHEMITSCH, E., McKEE, M., Complications of intramedullary nailing for fractures of the humeral shaft: a review. J Orthop Trauma 1999;13:258-67. 
8. BELL, M., BEAUCHAMP, C., MCMURTY, R., The results of plating humeral shaft fractures in patients with multiple injuries. J Bone Joint Surg Brit Vol 1985;67:293-6.

9. DABEZIES, E.J., BANTA, C.J ${ }^{\text {2nd }}$, MURPHY, C.P., D’AMBROSIA, R.D., Plate fixation of the humeral shaft for acute fractures, with and without radial nerve injuries. J Orthop Trauma 1992;6: 10-13.

10.HOLSTEIN, A., LEWIS, G.M., Fractures of the humerus with radial nerve paralysis. J Bone Joint Surg 1963;45:1382-8.

11. PACKER, J.W., FOSTER, R.R., GARCIA, A., GRANTHAM, S.A., The humeral fracture with radial nerve palsy: is exploration warranted? Clin Orthop Relat Res 1972;88:34-38.

12. BUMBASIREVIC, M., LESIC, A., BUMBASIREVIC, V., COBELJIC, G., MILOSEVIC, I., ATKINSON, H.D., The management of humeral shaft fractures with associated radial nerve palsy: a review of 117 cases. Arch Orthop Trauma Surg 2010;130:519-22.

13. LOWE, J., SEN, S., Mackinnon S. Current approach to radial nerve paralysis. Plastic Reconstr Surg 2002;110:1099-112

14.FU, S.Y., GORDON, T., Contributing factors to poor functional recovery after delayed nerve repair: prolonged denervation. J Neurosci 1995;15:3886-95.

15. SMITH, R.J., Tendon transfers to restore wrist and digit extensions. In: Tendon transfers of the hand and forearm. Boston: Little, Brown; 1987:35-56.

16. ANGHEL, L., BAROIU, L., BEZNEA, A., TOPOR, G., GRIGORE, C.A., The Therapeutic Relevance of Vitamin E, Rev Chim (Bucharest), 70, no.10, 2019, p. 3711-3713.

17.BAROIU, L., BEZNEA, A., CONDRATOVICI, C.P., ONISOR, C., GRIGORE, C.A., TOPOR, G., RUGINA, S., Comparative Effectiveness of Vancomycin and Metronidazole for the Initial Episode of Nonsevere Clostridium Difficle Infection, Rev Chim (Bucharest), 70, no.10, 2019, p. 37413745 .

18.KOZIN, S.H., Tendon transfers for radial and median nerve palsies. J Hand Ther 2005;18:208-215.

19.LI, Z., QIN, H., FENG, Z., et al. Human umbilical cord mesenchymal stem cell-loaded amniotic membrane for the repair of radial nerve injury. Neural Regen Res 2013;8:3441-3448.

20.OPROIU, A.M., LASCAR, I., DONTU, O., FlOREA, C., SCARLET, R., SEBE, I., DOBRESCU, L., MOLDOVAN, C., NICULAE, C., CERGAN, R., BESNEA, D., CISMAS, S., DAVID, D., MURARU, D., NEAGU, T., POGARASTEANU,M.E., STOICA, C., EDU,A., IFRIM, C.F., Topography of the Human Ulnar Nerve for Mounting a Neuro-Prosthesis with Sensory,http://www.revistadechimie.ro, Rev.Chim.(Bucharest),69, no. 12, 2018, p.3748, Feedback, Rev. Chim. (Bucharest), 69, no. 9, 2018, p. 2494-2497

21. OPROIU, A. M., LASCAR, I., MOLDOVAN, C., DONTU, O., PANTAZICA, M., MIHAILA, C. FlOREA, C., DOBRESCU, L., SEBE, I., SCARLET, R., DOBRESCU, D., NEAGU, T., IONESCU, O., STOICA I.C., EDU, A., Peripheral Nerve WIFI Interfaces and Electrodes for Mechatronic Prosthetic Hand, ROMJIST, Volume 21, Number 2, 2018, pp. 129-138.

22. CRETU, M.S., GRIGORE, A.C., MAIER, A., POPA, T.O., CONDRATOVICI, A.P., DOROBAT, C., PAVEL, L.L., CHESARU, I.B., Early Stratification of Sepsis Using Presepsine in Emergency Department (North-East of Romania Experience). Mat.Plast., 54, no.1, 2017, p.190-193.

23. PAVEL, L.L., TIUTIUCA, C., BERBECE, S.I., CONDRATOVICI, A.P., IOANID, N., Chemical Physiology of Muscle Contraction, Rev.Chim.(Bucharest), 68, no.5, 2017, p.1095-1097

Manuscript received: 10.01 .2020 